\title{
Association of urinary 8-OHdG with lifestyle and body composition in elderly natural disaster victims living in emergency temporary housing
}

\author{
Kimie Saito $\cdot$ Hagiko Aoki $\cdot$ Naoshi Fujiwara $\cdot$ \\ Masahiro Goto $\cdot$ Chikako Tomiyama · \\ Yuka Iwasa
}

Received: 5 October 2011/ Accepted: 23 April 2012/Published online: 24 May 2012

(C) The Japanese Society for Hygiene 2012

\begin{abstract}
Objectives Residents who lost land and houses due to disasterous heavy rainfall-related events on July 13, 2004 and the Chuetsu Earthquake on October 23, 2004 were moved to emergency temporary housing. The change in life style due to living under such conditions is assumed to increase oxidative stress level. In this study, we investigated the oxidative stress level in elderly residents of emergency temporary housing, and analyzed its association with lifestyle and body composition following these disasters.

Methods A noninvasive oxidative stress marker, urinary 8-hydroxydeoxyguanosine (8-OHdG), and body composition were measured in 73 elderly residents of emergency temporary housing.

Results In the elderly female residents, the urinary 8-OHdG level tended to decrease with time after the disasters. 8-OHdG levels were slightly higher in females than males and significantly higher among those who exercised regularly compared to those who did not, particularly in females. A weak correlation was noted between the urinary 8-OHdG level and muscle ratio in females.

Conclusions The in vivo oxidative stress level in our study cohort of elderly residents of emergency temporary housing changed following the change in life style, but remained within the normal range. The increase in oxidative stress levels of elderly females was related to menopause. A decrease in estrogen levels due to menopause
\end{abstract}

K. Saito $(\bowtie) \cdot$ H. Aoki · N. Fujiwara $\cdot$ M. Goto

C. Tomiyama $\cdot$ Y. Iwasa

School of Health Sciences, Faculty of Medicine,

Niigata University, 2-746 Asahimachi-dori,

Chuo-ku, Niigata City, Niigata 951-8518, Japan

e-mail: kimi@clg.niigata-u.ac.jp inhibits its antioxidant effects, which increases 8-OHdG levels. Although it is difficult to determine, a decrease in daily stressors over time following the disaster could be a cause of the decrease in oxidative stress levels. We suggest that the close evaluation of the stress level of disaster victims is desirable, in combination with evidence of antioxidative substances and the psychosocial influence of suffering as a consequence of the disaster.

Keywords Disaster - Emergency temporary housing . 8-Hydroxy-2'-deoxyguanosine - In vivo oxidative stress . Elderly

\section{Introduction}

Niigata prefecture in Japan was hit by two major disasters in 2004. Heavy rainfall caused floods centering in Sanjo City on July 13, and the Chuetsu Earthquake occurred on October 23. Victims who lost houses and land moved into emergency temporary housing after staying in shelters during the middle of August in the flood region and early December in the region hit by the earthquake.

Residents of emergency temporary housing experience difficulties in maintaining/resuming normal daily living activities due to the forced abandonment of their homes and the inadequacy of such housing for long-term residency. The influences of cold weather, snowfall, heat, and humidity in the rainy season and a restricted living space can all have an effect on these residents. It has been reported that the restoration and reconstruction of houses is difficult for elderly victims, prolonging their stay in emergency temporary housing [1], and that changes in living environments impair their mental and physical condition [2]. 
Evaluation of the oxidative stress level and taking measures to reduce oxidative stress are expected to be useful approaches by which to clarify the pathological condition, diagnose diseases before manifestation, prevent diseases, and control aging [3]. There have been several published evaluations on the in vivo stress levels of disaster victims and emigrants, including reports of a high cortisol level in individuals who experienced earthquakes [4], a reduction of the salivary cortisol level in ice storm victims that lasted from 1 month to longer than 1 year after the disaster [5], reduced thyroid stimulating hormone and thyroid hormone levels 6 weeks after immigration [6], a low interleukin-2 level in post-traumatic stress disorder (PTSD) patients after a disaster and its association with depression and anxiety symptoms [7], and a high leptin level in PTSD patients after a disaster [8]. However, in vivo stress in victims living in emergency temporary housing has not been evaluated, indicating that the oxidative stress level has also not been investigated in such disaster victims.

8-Hydroxydeoxyguanosine $(8-\mathrm{OHdG})$ is an oxidative stress marker, and in vivo oxidative stress can be noninvasively evaluated based on urinary $8-\mathrm{OHdG}$ levels. The objective of this test includes investigation of the mutageninduced cancer risk, evaluation of lifestyle, detection of accelerated aging, pathological analysis of diseases involving oxidative stress, survey of biological influences of radiation/environmental pollutants, and measurement of biological effects of antioxidative substances [3]. Influences of lifestyle and physique on the $8-\mathrm{OHdG}$ level have been observed in various surveys. It has been reported that the 8-OHdG level is higher in males than in females, in thin than in obese persons [9], and in cigarette smokers, that passive smoking has no influence on 8-OHdG level [10], that the 8-OHdG level decreases in persons who stop cigarette smoking [11], and that a reduction in body mass index (BMI) and an increase in 8-OHdG level are associated [12].

In one study, moderate exercise and age were associated with a reduced $8-\mathrm{OHdG}$ level, while heavy labor, a low meat intake, and working in a two-shift system were associated with increases in 8-OHdG level [13]. In two other studies, habitual alcohol drinking with colleagues, a long working day, and work worth doing were associated with an elevation in 8-OHdG level [14], and daily exercise and a healthy diet were associated with a reduction in 8-OHdG level [15]. These results suggest that $8-\mathrm{OHdG}$ is influenced not only by lifestyle but also by physical activity and lead to the notion that in vivo oxidative stress levels in elderly victims living in temporary housing may be influenced by their levels of activity following the disaster, as well as their dietary, drinking, and smoking habits. A sharp increase in in vivo oxidative stress levels is considered to indicate an increased health risk.
Detailed investigation of in vivo oxidative stress is possible by employing a combination of antioxidative substances and other oxidative damage markers as a comprehensive oxidative stress evaluation [3]. In the survey reported here, we took into account the burden of such an investigation on the elderly subjects and adopted only the noninvasive urinary $8-\mathrm{OHdG}$ measurement as an in vivo oxidative stress marker. We subsequently analyzed the association of urinary $8-\mathrm{OHdG}$ level with the lifestyle and body composition of the elderly residents of temporary housing, as these factors influence oxidative stress. The purpose of the survey was to analyze the relationship between oxidative stress levels in victims following a disaster, their lifestyle habits, and body composition.

Since the concept of 'stress' is broad, oxidative stress produced in the body, such as DNA damage due to reactive oxygen, is considered to be 'in vivo oxidative stress' in this study.

\section{Subjects and methods}

This study was performed after approval by the Ethics Committee of Niigata University School of Medicine (approval date 2 August 2005; study number 371).

The study period was between August 2005 and June 2006. The survey was performed four times: August and November 2005 and February and June 2006, at public meeting places located near emergency temporary housing built in the disaster-stricken areas. Brochures describing the interview and the physical fitness and stress measurements were distributed to all households living in the emergency temporary housing before the survey to disseminate information, and subjects participated in the survey based on their own free will. Written informed consent was acquired from all the participants.

The subjects were aged 60 years or older. Blood pressure, height, body weight, muscle and body fat rates, and BMI were measured. The presence or absence of consultation with medical institutions and diseases, medication, cigarette smoking, alcohol drinking, and exercise habits were surveyed by interviews. In addition, primary urine was collected to evaluate stress based on the oxidative stress marker 8-OHdG.

For the urinary $8-\mathrm{OHdG}$ measurement, urine samples were immediately frozen at the location of the survey and stored at $-30{ }^{\circ} \mathrm{C}$ until immediately before analysis. 8-OHdG was measured by an enzyme-linked immunosorbent assay (ELISA) using a commercial analytical kit (Japan Institute for Control of Aging, Nikken SEIL Co., Fukuroi, Shizuoka, Japan). Since casual urine was used, the 8-OHdG level was corrected by the urinary creatinine (Cre) level. Urinary creatinine was measured employing the Jaffé method. 
Statistical analysis

For the statistical analysis of the urinary $8-\mathrm{OHdG}$ level (corrected by the creatinine level), the mean was compared using the Kruskal-Wallis non-parametric test. For comparison by gender, the presence or absence of consultation with a medical institution, medication, and lifestyle, the Mann-Whitney $U$ test was employed. $P<0.05$ was regarded indicating significance. Since this research was an exploratory study and the number of subjects was not fully sufficient, in consideration of false negative results, i.e., beta error, $P<0.1$ was taken as suggestive significance. Spearman's correlation coefficients were calculated for the association of the urinary $8-\mathrm{OHdG}$ level with age and various body composition values. These analyses were performed using statistical analysis software (PASW ver 17.0; SPSS, Chicago, IL). Body composition was measured using a body composition monitor (Karada Scan HBF3541T-2; Omron Healthcare Co, Lake Forest, IL).

\section{Results}

A total of 132 subjects participated in the survey, and 74 subjects provided urine samples for $8-\mathrm{OHdG}$ measurement. Since urinary $8-\mathrm{OHdG}$ is influenced by cancer [3], one subject with cancer was excluded from the analysis, and thus the final number of subjects who provided a urine sample was 73 . The mean age of all subjects was $72.3 \pm 6.4$ years (range 60-88 years), and the final study cohort comprised 20 males $(27.4 \%)$ and 53 females $(72.6 \%)$. Sixty-four subjects lived in the region hit by the Chuetsu earthquake, and the most common household consisted of two people living together as a married couple.

The mean urinary $8-\mathrm{OHdG}$ level in all subjects was $12.1 \pm 6.8 \mathrm{ng} / \mathrm{mg}$ Cre $(n=73)$ (Table 1$)$. There was no association between age and urinary 8 -OHdG level, and there was no significant difference in the urinary $8-\mathrm{OHdG}$ level due to the presence or absence of consultation at medical institution, cigarette smoking, or alcohol drinking. By gender, the mean levels were higher in females than in males $(P=0.056)$.

The urinary 8-OHdG level in subjects who habitually performed exercise and worked on a farm was $13.0 \pm 6.9 \mathrm{ng} / \mathrm{mg}$ Cre $(n=43)$, which was significantly higher than that in subjects who did not perform routine exercise (9.9 $\pm 6.3 \mathrm{ng} / \mathrm{mg}$ Cre; $n=23 ; P=0.030)$.

The mean urinary $8-\mathrm{OHdG}$ levels in females tended to decrease with time over the four survey time points $(P=0.069)$. By gender, no changes with time were noted in any of the body composition values (Table 2).

The correlations between age and muscle and body fat rates and $\mathrm{BMI}$ and the urinary $8-\mathrm{OHdG}$ level were investigated by gender. A correlation chart of the muscle rate is shown in Fig. 1. A weak correlation was observed in females, showing a significant difference $(r=0.30$, $P=0.036)$. No correlation was noted between body fat rate and urinary $8-\mathrm{OHdG}$ level. A significant correlation between age and muscle rate was also observed $(r=$ $-0.497, P<0.001)$.

The mean urinary $8-\mathrm{OHdG}$ levels were $13.6 \pm 6.4$ $(n=36)$ and $10.3 \pm 7.2 \mathrm{ng} / \mathrm{mg}$ Cre $(n=15)$ in females who did and did not routinely exercise, respectively

Table 1 Background demographic/clinical data and urinary 8-hydroxydeoxyguanosine level in residents of temporary housing

\begin{tabular}{|c|c|c|c|}
\hline \multirow[t]{2}{*}{ Demographic/clinical data } & \multicolumn{3}{|c|}{ Urinary 8-OHdG level (ng/mg Cre } \\
\hline & $n(\%)$ & Mean $\pm \mathrm{SD}$ & $P$ value \\
\hline Overall & $73(100)$ & $12.1 \pm 6.8$ & \\
\hline \multicolumn{4}{|l|}{ Age (years) } \\
\hline Mean \pm SD & \multicolumn{3}{|c|}{$72.3 \pm 6.4(60-88)$} \\
\hline $60-69$ & $31(42.5)$ & $12.2 \pm 5.9$ & 0.744 \\
\hline $70-79$ & $32(43.8)$ & $11.3 \pm 6.6$ & \\
\hline $80-89$ & $10(13.7)$ & $14.4 \pm 9.7$ & \\
\hline \multicolumn{4}{|l|}{ Gender } \\
\hline Male & $20(27.4)$ & $10.4 \pm 6.9$ & $0.056^{\dagger}$ \\
\hline Female & $53(72.6)$ & $12.7 \pm 6.7$ & \\
\hline \multicolumn{4}{|l|}{ Disaster region } \\
\hline Flood & $9(12.3)$ & $12.1 \pm 5.0$ & 0.737 \\
\hline Earthquake & $64(87.7)$ & $12.1 \pm 7.0$ & \\
\hline \multicolumn{4}{|l|}{ Residence form } \\
\hline Living alone & $6(8.8)$ & $10.9 \pm 4.9$ & 0.115 \\
\hline Married couple & $48(70.6)$ & $11.2 \pm 4.8$ & \\
\hline 3 generations living together & $14(20.6)$ & $17.4 \pm 10.5$ & \\
\hline \multicolumn{4}{|c|}{ Consultation at medical institution } \\
\hline Yes & $58(79.5)$ & $11.6 \pm 6.0$ & 0.685 \\
\hline No & $14(19.2)$ & $13.8 \pm 9.3$ & \\
\hline \multicolumn{4}{|l|}{ Medication } \\
\hline Yes & $61(84.7)$ & $12.2 \pm 7.2$ & 0.988 \\
\hline No & $11(15.3)$ & $11.2 \pm 4.0$ & \\
\hline \multicolumn{4}{|l|}{ Cigarette smoking habit } \\
\hline Yes & $8(11.1)$ & $11.9 \pm 3.7$ & 0.603 \\
\hline No & $64(88.9)$ & $12.1 \pm 7.1$ & \\
\hline \multicolumn{4}{|l|}{ Alcohol drinking habit } \\
\hline Yes & $29(40.3)$ & $10.7 \pm 5.8$ & 0.174 \\
\hline No & $43(59.7)$ & $12.9 \pm 7.3$ & \\
\hline \multicolumn{4}{|l|}{ Exercise habit } \\
\hline Yes & $48(67.6)$ & $13.0 \pm 6.9$ & $0.030^{*}$ \\
\hline No & $23(32.4)$ & $9.9 \pm 6.3$ & \\
\hline
\end{tabular}

$* P<0.05,{ }^{\dagger} P<0.1$ by Mann-Whitney $U$ test or the Kruskal Wallis non-parametric test

8-OHdG, 8-Hydroxydeoxyguanosine, Cre creatinine, SD standard deviation 
Table 2 Changes in urinary 8-OHdG level and body composition with increasing residency time in temporary housing

\begin{tabular}{|c|c|c|c|c|c|c|c|c|c|c|c|}
\hline \multirow{2}{*}{$\begin{array}{l}\text { Demographic/clinical } \\
\text { data }\end{array}$} & \multicolumn{2}{|c|}{ Overall } & \multicolumn{2}{|c|}{ August 2005} & \multicolumn{2}{|c|}{ November 2005} & \multicolumn{2}{|c|}{ February 2006} & \multicolumn{2}{|c|}{ June 2006} & \multirow{2}{*}{$\begin{array}{l}\text { All } 4 \\
\text { periods } \\
P \text { value }\end{array}$} \\
\hline & $n$ & Average $\pm S D$ & $n$ & Average \pm SD & $n$ & Average $\pm \mathrm{SD}$ & $n$ & Average $\pm \mathrm{SD}$ & $n$ & Average $\pm \mathrm{SD}$ & \\
\hline \multicolumn{12}{|l|}{ Male } \\
\hline Age & 20 & $74.8 \pm 6.3$ & 5 & $76.8 \pm 6.1$ & 1 & 69.0 & 6 & $73.3 \pm 4.3$ & 8 & $75.4 \pm 8.1$ & 0.552 \\
\hline Weight (kg) & 19 & $57.4 \pm 8.0$ & 4 & $57.7 \pm 11.9$ & 1 & 59.0 & 6 & $58.4 \pm 7.8$ & 8 & $69.8 \pm 7.5$ & 0.975 \\
\hline Muscle rate $(\%)$ & 18 & $24.9 \pm 2.0$ & 4 & $25.7 \pm 3.1$ & 1 & 26.2 & 5 & $24.3 \pm 1.5$ & 8 & $24.6 \pm 1.8$ & 0.740 \\
\hline Body fat rate $(\%)$ & 18 & $27.9 \pm 3.0$ & 4 & $26.7 \pm 3.9$ & 1 & 25.7 & 5 & $29.3 \pm 2.3$ & 8 & $27.8 \pm 3.1$ & 0.419 \\
\hline BMI & 18 & $23.7 \pm 2.5$ & 4 & $22.9 \pm 3.9$ & 1 & 24.7 & 5 & $24.7 \pm 2.0$ & 8 & $23.4 \pm 2.2$ & 0.519 \\
\hline $\begin{array}{l}\text { Urinary 8-OHdG } \\
\text { level (ng/mg Cre) }\end{array}$ & 20 & $10.4 \pm 6.9$ & 5 & $11.8 \pm 4.1$ & 1 & 10.9 & 6 & $13.3 \pm 11.5$ & 8 & $7.4 \pm 2.6$ & 0.118 \\
\hline \multicolumn{12}{|l|}{ Female } \\
\hline Age & 53 & $80.0 \pm 6.2$ & 15 & $68.5 \pm 5.2$ & 19 & $73.4 \pm 6.7$ & 16 & $71.7 \pm 5.3$ & 3 & $70.0 \pm 8.7$ & 0.164 \\
\hline Weight (kg) & 53 & $53.3 \pm 8.6$ & 15 & $50.7 \pm 6.9$ & 19 & $48.0 \pm 9.0$ & 16 & $53.4 \pm 10.0$ & 3 & $50.4 \pm 3.8$ & 0.410 \\
\hline Muscle rate $(\%)$ & 50 & $21.5 \pm 2.7$ & 15 & $22.1 \pm 1.6$ & 16 & $21.8 \pm 4.1$ & 16 & $21.1 \pm 1.9$ & 3 & $19.6 \pm 1.9$ & 0.232 \\
\hline Body fat rate $(\%)$ & 50 & $34.6 \pm 4.6$ & 15 & $33.7 \pm 3.7$ & 16 & $33.5 \pm 5.2$ & 16 & $36.0 \pm 4.6$ & 3 & $37.7 \pm 3.6$ & 0.137 \\
\hline BMI & 50 & $24.0 \pm 3.7$ & 15 & $23.6 \pm 2.8$ & 16 & $22.8 \pm 3.0$ & 16 & $25.2 \pm 4.7$ & 3 & $25.6 \pm 3.1$ & 0.291 \\
\hline $\begin{array}{l}\text { Urinary 8-OHdG } \\
\text { level (ng/mg Cre) }\end{array}$ & 53 & $12.7 \pm 6.7$ & 15 & $11.9 \pm 4.5$ & 19 & $14.9 \pm 7.7$ & 16 & $12.1 \pm 6.9$ & 3 & $6.9 \pm 3.0$ & $0.069^{\dagger}$ \\
\hline
\end{tabular}

${ }^{\dagger} P<0.1$ by the Kruskal-Wallis non-parametric test

BMI Body mass index

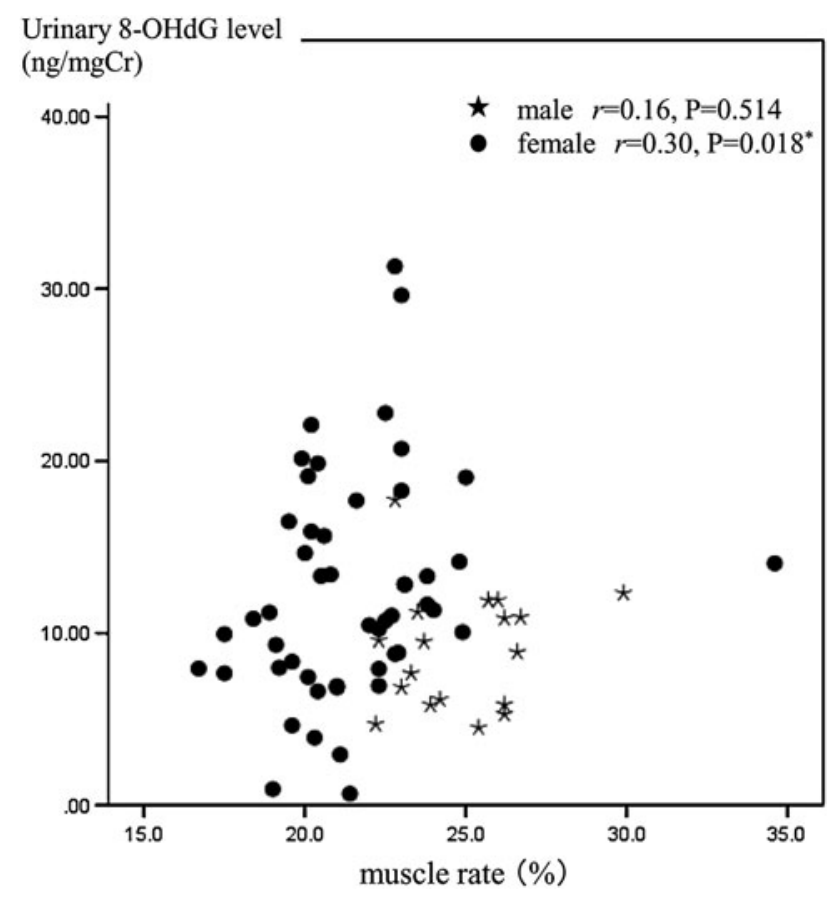

Fig. 1 Relationship between the urinary 8-hydroxydeoxyguanosine (8-OHdG) level and muscle rate by gender. $r$ Spearman's correlation coefficient. $P<0.05$ indicated significance of calculated correlation

$(P=0.043)$ (Table 3). Body weight was significantly lower in females who routinely exercised $(P=0.014)$ and the body fat rate was slightly lower $(P=0.052)$.

\section{Discussion}

The in vivo oxidative stress level, i.e., the level of stress inducing oxidative DNA damage in the body, and the relationship between oxidative stresses, life style habit, and the body composition were surveyed in elderly residents of emergency temporary housing who had experienced a natural disaster.

The standard level of urinary 8-OHdG (corrected by the Cre level) employed as a stress marker, as provided by the manufacturer of the measurement kit, is $8.4 \mathrm{ng} / \mathrm{mg}$ Cre [16], and that reported as the standard for healthy adults is $15.7 \mathrm{ng} / \mathrm{mg}$ Cre [3]. The urinary $8-\mathrm{OHdG}$ in the elderly disaster victims was slightly lower than that in healthy subjects aged 60 years or older [17] and higher than that in healthy subjects aged 40 years or older [18].

Moreover, the level measured in our study may have been lower than that in workers exposed to carcinogens $[15,19,20]$. Consequently, the influence of changes in the living environment, represented in our study as emergency temporary housing, appears to fall within the standard range of changes in in vivo oxidative stress level encountered in daily life activities, and not as rapid changes caused by harmful chemicals.

While some studies reported a rise in urinary $8-\mathrm{OHdG}$ level with age $[10,18,21]$, other studies found no agerelated difference [19]. In terms of an association between gender and urinary $8-\mathrm{OHdG}$ level, urinary $8-\mathrm{OHdG}$ has 
Table 3 Association between routine exercise habits and urinary 8-OHdG level and body composition

\begin{tabular}{|c|c|c|c|c|c|}
\hline \multirow{3}{*}{$\begin{array}{l}\text { Demographic/ } \\
\text { clinical data }\end{array}$} & \multicolumn{4}{|c|}{ Regular exercise routine } & \multirow[t]{3}{*}{$P$ value } \\
\hline & \multicolumn{2}{|c|}{ Yes } & \multicolumn{2}{|c|}{ No } & \\
\hline & $n$ & Average \pm SD & $n$ & Average \pm SD & \\
\hline \multicolumn{6}{|l|}{ Age } \\
\hline Male & 12 & $75.4 \pm 4.9$ & 8 & $73.9 \pm 8.4$ & 0.440 \\
\hline Female & 36 & $71.4 \pm 6.3$ & 15 & $72.0 \pm 5.6$ & 0.576 \\
\hline \multicolumn{6}{|l|}{ Weight $(\mathrm{kg})$} \\
\hline Male & 11 & $57.0 \pm 8.0$ & 8 & $57.9 \pm 8.5$ & 0.804 \\
\hline Female & 36 & $48.4 \pm 7.8$ & 15 & $55.4 \pm 8.8$ & $0.014 *$ \\
\hline \multicolumn{6}{|l|}{ Creatinine } \\
\hline Male & 12 & $96.2 \pm 73.7$ & 8 & $73.5 \pm 35.3$ & 0.537 \\
\hline Female & 36 & $48.1 \pm 43.8$ & 15 & $53.8 \pm 31.1$ & 0.264 \\
\hline \multicolumn{6}{|l|}{ Muscle rate $(\%)$} \\
\hline Male & 10 & $24.7 \pm 1.6$ & 8 & $25.1 \pm 2.5$ & 0.859 \\
\hline Female & 34 & $21.7 \pm 3.0$ & 14 & $20.9 \pm 1.9$ & 0.482 \\
\hline \multicolumn{6}{|c|}{ Body fat rate $(\%)$} \\
\hline Male & 10 & $27.9 \pm 2.1$ & 8 & $27.8 \pm 4.1$ & 1.000 \\
\hline Female & 34 & $33.8 \pm 4.5$ & 14 & $36.8 \pm 4.4$ & $0.052^{\dagger}$ \\
\hline \multicolumn{6}{|l|}{ BMI } \\
\hline Male & 10 & $23.7 \pm 2.4$ & 8 & $23.7 \pm 2.7$ & 0.894 \\
\hline Female & 34 & $23.4 \pm 2.9$ & 14 & $25.6 \pm 4.8$ & 0.170 \\
\hline \multicolumn{6}{|c|}{ Urinary 8-OHdG level (ng/mg Cre) } \\
\hline Male & 12 & $11.2 \pm 8.3$ & 8 & $9.3 \pm 4.3$ & 0.589 \\
\hline Female & 36 & $13.6 \pm 6.4$ & 15 & $10.3 \pm 7.2$ & $0.043^{*}$ \\
\hline
\end{tabular}

$* P<0.05,{ }^{\dagger} P<0.1$ by Mann-Whitney $U$ test or the Kruskal Wallis non-parametric test

been reported to be higher in males than in females $[9,10$, 14], but the gender difference was resolved after correction by the creatinine level [3]. Previous studies found that the 8-OhdG level rises in females after menopause, becoming higher than that in males $[18,22]$. A decrease in estrogen levels due to menopause inhibits its antioxidant effects, which increases 8-OhdG levels [18]. As the subjects of our survey were mainly elderly in their sixties and seventies, the increase in vivo oxidative stress levels could be attributed to menopause.

Previous studies found an association between BMI reduction and elevated urinary $8-\mathrm{OHdG}$ levels $[12,18]$. In our survey, however, there was no correlation between urinary $8-\mathrm{OHdG}$ levels and the BMI, presumably because only two thin subjects participated in the study.

The muscle ratio in female subjects was weakly correlated with urinary $8-\mathrm{OHdG}$ levels. In general, urinary creatinine is excreted in the muscles, and the $8-\mathrm{OHdG}$ level is low in an individual with a high muscle ratio [23]. In our survey, there was a marked relationship between the muscle rate and aging, and there may be a bias related to higher urinary $8-\mathrm{OHdG}$ levels. Regarding the body composition of subjects, only the muscle ratio was low compared that reported in previous studies [24]. The muscle strength of the subjects in our study may not be sufficient to promote creatinine metabolism.

It has been reported that a long working day and physical labor elevate the urinary 8-OHdG level [25-27] and that daily and moderate exercise reduce it [13-15]. In addition, a significantly lower 8-OHdG level has been reported in the elderly who are fit compared to those considered unfit due to the difference in antioxidative enzyme activation [28]. This difference was explained as being due to the association between increased exercise and primary activity levels and in vivo oxidative stress levels. In our survey, farm work and walking performed by those who had lived in temporary housing for 1-2 years following the disaster were regarded as moderate levels of activity. The results of a previous study suggest that sedentary older individuals would lack habitual mild stress and therefore would have a much slower response, or possibly lose to transient increases of reactive oxygen species [28]. This phenomenon could be related to the lower urinary 8-OHdG level in the group of subjects who had not developed regular exercise habits. However, our examination was performed during their resting time, not during exercise training, so the relationship between these activities and the antioxidant capacity has not yet been clarified.

Although in vivo oxidative stress decreased over time in our study cohort of elderly living in temporary housing following a disaster, stress levels were not affected by their body composition and lifestyle habits. We assume that lifestyle habits did not have significant influence because most subjects were females and there were no marked differences in their alcohol consumption and smoking habits.

In one study, reduced adrenocortical hormone secretion was determined in individuals 1 year after experiencing an ice storm disaster [5], and the cortisol and 8-OHdG levels were correlated [14]. Although it is difficult to determine, a decrease in daily stressors over time following the two disasters could explain the decrease in oxidative stress levels in our study.

In a previous study, researchers profiled oxidative stress in combination with measurements of urinary lipids and proteins [27]. Psychosocial stress of the victims was not evaluated in our study. associations between psychological trauma and immunological stress in victims [29] have been reported. Comprehensive evaluation of stress in victims by combining the psychosocial influence with evidence of in vivo oxidative may lead to appropriate support for disaster victims.

Acknowledgments We are grateful to Akiko Kuribayashi, Yuka Abe, and Ritsuko Higuchi, public health nurses of Sanjo City, Misako 
Hoshino, Keiko Suzuki, and Yayoi Takagi, public health nurses of Nagaoka City, and Nozomi Tochiki, a graduate student of Niigata University (currently a researcher at Kyoto Prefectural University of Medicine).

Conflict of interest This study was partially supported by Grant-inAid for Scientific Research (C).

\section{References}

1. Aoki H, Saito K, Hyodo K, Nagata A, Shimizu U, Goto M, et al. Two natural disasters and support activities for residents of emergency temporary housing (in Japanese). Bull School Health Sci Niigata Univ. 2007;8(3):97-102.

2. Ikeda S, Yamamoto Y, Nakano C, Nogawa K, Ohno K, Hosomi A, et al. The following up study on daily life and health of elderly victims in public housing after the Hanshin-Awaji earthquake (in Japanese). J Jpn Soc Disaster Nurs. 2002;4(1):46-60.

3. Ochi H, Iida M, Sakai K. Urinary 8-OHDG (8-hydroxy-2'deoxyguanosine) (in Japanese). Nippon Rinsho. 2004;62:541-3.

4. Song Y, Zhou D, Wang X. Increased serum cortisol and growth hormone levels in earthquake survivors with PTSD or subclinical PTSD. Psychoneuroendocrinology. 2008;33(8):1155-9.

5. Anisman H, Griffiths J, Matheson K, Ravindran AV, Merali Z. Posttraumatic stress symptoms and salivary cortisol levels. Am J Psychiatry. 2001;158(9):1509-11.

6. Bauer M, Priebe S, Gräf KJ, Kürten I, Baumgartner A. Psychological and endocrine abnormalities in refugees from East Germany: Part II. Serum levels of cortisol, prolactin, luteinizing hormone, follicle stimulating hormone, and testosterone. Psychiatry Res. 1994;51(1):75-85.

7. Song Y, Zhou D, Guan Z, Wang X. Disturbance of serum interleukin-2 and interleukin-8 levels in posttraumatic and nonposttraumatic stress disorder earthquake survivors in northern China. Neuroimmunomodulation. 2007;14(5):248-54.

8. Liao SC, Lee MB, Lee YJ, Huang TS. Hyperleptinemia in subjects with persistent partial posttraumatic stress disorder after a major earthquake. Psychosom Med. 2004;66(1):23-8.

9. Loft S, Fischer-Nielsen A, Jeding IB, Vistisen K, Poulsen HE. 8-Hydroxydeoxyguanosine as a urinary biomarker of oxidative DNA damage. J Toxicol Environ Health. 1993;40(2-3):391-404.

10. Pilger A, Germadnik D, Riedel K, Meger-Kossien I, Scherer G, Rüdiger HW. Longitudinal study of urinary 8-hydroxy-2'-deoxyguanosine excretion in healthy adults. Free Radic Res. 2001;35(3):273-80.

11. Priemé H, Loft S, Klarlund M, Grønbaek K, Tønnesen P, Poulsen HE. Effect of smoking cessation on oxidative DNA modification estimated by 8 -oxo-7,8-dihydro-2'-deoxyguanosine excretion. Carcinogenesis. 1998;19(2):347-51.

12. Mizoue T, Tokunaga S, Kasai H, Kawai K, Sato M, Kubo T. Body mass index and oxidative DNA damage: a longitudinal study. Cancer Sci. 2007;98(8):1254-8.

13. Kasai H, Iwamoto-Tanaka N, Miyamoto $\mathrm{T}$, Kawanami K, Kawanami S, Kido R, et al. Life style and urinary 8-hydroxydeoxyguanosine, a marker of oxidative DNA damage: effects of exercise, working conditions, meat intake, body mass index, and smoking. J Cancer Res. 2001;92(1):9-15.
14. Irie M, Tamae K, Iwamoto-Tanaka N, Kasai H. Occupational and lifestyle factors and urinary 8-hydroxydeoxyguanosine. Cancer Sci. 2005;96(9):600-6.

15. Tamae K, Kawai K, Yamasaki S, Kawanami K, Ikeda M, Takahashi K, et al. Effect of age, smoking and other lifestyle factors on urinary 7-methylguanine and 8-hydroxydeoxyguanosine. Cancer Sci. 2009;100(4):715-21.

16. Japan Institute for the Control of Aging (JaICA). Nikken SEIL Co. Fukuroi, Shizuoka, Japan. Available at: http://www.jaica. $\mathrm{com} /$.

17. Kimura S, Yamauchi H, Hibino Y, Iwamoto M, Sera K, Ogino K. Evaluation of urinary 8-hydroxydeoxyguanine in healthy Japanese people. Basic Clin Pharmacol Toxicol. 2006;98(5):496-502.

18. Sakano N, Wang DH, Takahashi N, Wang B, Sauriasari R, Kanbara $\mathrm{S}$, et al. Oxidative stress biomarkers and lifestyles in Japanese healthy people. J Clin Biochem Nutr. 2009;44(2): $185-95$.

19. Hong YC, Park HS, Ha EH. Influence of genetic susceptibility on the urinary excretion of 8-hydroxydeoxyguanosine of firefighters. Occup Environ Med. 2000;57(6):370-5.

20. Lai CH, Liou SH, Lin HC, Shih TS, Tsai PJ, Chen JS, et al. Exposure to traffic exhausts and oxidative DNA damage. Occup Environ Med. 2005;62(4):216-22.

21. Miwa M, Matsumaru H, Akimoto Y, Naito S, Ochi H. Quantitative determination of urinary 8-hydroxy-2'-deoxyguanosine level in healthy Japanese volunteers. Biofactors. 2004;22(1-4): 249-53.

22. Nakano M, Kawanishi Y, Kamohara S, Uchida Y, Shiota M, Inatomi $\mathrm{Y}$, et al. Oxidative DNA damage (8-hydroxydeoxyguanosine) and body iron status: a study on 2507 healthy people. Free Radic Biol Med. 2003;35(7):826-32.

23. Aoi Y, Takanami Y. Undo to Sanka stress. In: Yoshikawa T, editor. Sanka stress no igaku (in Japanese). Tokyo: Shindan to chiryo sha; 2008. p. 346-52.

24. Namba H, Tanabe K, Yokoyama N, Suga Y, Nakano T, Sato H, et al. Development of multiple regression models to estimate physical fitness for middle-aged and elderly persons. Jpn J Clin Sports Med. 2009;17(3):506-14.

25. Kambayashi I, Ishimura N, Nakamura T, Uchida E, Takeda H, Fujii $\mathrm{H}$. Urinary $8-\mathrm{OHdG}$ content increases after short-term and high-intensity intermittent exercise (in Japanese). J Exerc Sports Physiol. 2004;11(2):61-7.

26. Mimura K, Kobayashi T, Mizukoshi S. A study of quantification of oxidative stresses caused by lifestyle habits (in Japanese). Rinsho Byori. 2007;55:35-40.

27. Orhan H, van Holland B, Krab B, Moeken J, Vermeulen NP, Hollander P, et al. Evaluation of a multi-parameter biomarker set for oxidative damage in man: increased urinary excretion of lipid, protein and DNA oxidation products after one hour of exercise. Free Radic Res. 2004;38(12):1269-79.

28. Traustadóttir T, Davies SS, Su Y, Choi L, Brown-Borg HM, Roberts LJ 2nd, et al. Oxidative stress in older adults: effects of physical fitness. Age (Dordr). 2011. Epub ahead of print.

29. Fukuda S, Morimoto K, Mure K, Maruyama S. Effect of the Hanshin-Awaji earthquake on posttraumatic stress, lifestyle changes, and cortisol levels of victims. Arch Environ Health. 2000;55(2):121-5. 